\title{
DIAGRAMA DA IMPRESSÃO E SUAS CONEXÕES COM A PALAVRA E A IMAGEM
}

\section{DIAGRAM OF PRINTING AND ITS CONNECTIONS WITH THE WORD AND THE IMAGE}

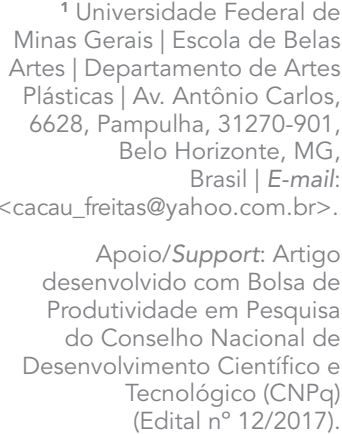

1 Universidade Federal de Minas Gerais | Escola de Belas Artes | Departamento de Artes Plásticas | Av. Antônio Carlos 6628, Pampulha, 31270-901 Belo Horizonte, MG Brasil | E-mail: <cacau_freitas@yahoo.com.br>

Apoio/Support: Artigo desenvolvido com Bolsa de Produtividade em Pesquisa do Conselho Nacional de Desenvolvimento Científico e Tecnológico (CNPq) (Edital $n^{\circ}$ 12/2017)

Maria do Carmo de Freitas Veneroso ${ }^{1}$

ORCID iD: 0000-0003-2851-9392

\section{RESUMO}

O presente artigo propõe uma discussão sobre a arte impressa, a partir de um diagrama da impressão, que parte da sua gênese na natureza até o seu desenvolvimento na arte na contemporaneidade. O diagrama estrutura-se a partir dos seguintes fatores: o anacronismo da impressão; continuidades, rupturas, cruzamentos e contaminações e o campo ampliado da gravura, temas que a autora já está pesquisando e no qual tem se aprofundando há algum tempo. Dentre os momentos de ruptura que mais afetaram a gravura e a arte impressa, destacam-se: o desenvolvimento da imprensa no ocidente; a invenção e o desenvolvimento da fotografia; a revolução/ proliferação digital. O diagrama aborda ainda o princípio comum da impressão, da palavra e da imagem, e sua vinculação desde a pré-história até o Renascimento, quando ocorre uma primeira ruptura entre a palavra e a imagem, que afetará também a gravura. Essa relação palavra/imagem será retomada no final do século XIX e início do século XX no trabalho de artistas e poetas que explorarão esse diálogo muitas vezes através de processos gráficos, diluindo a hierarquização entre palavra e imagem e retomando, dessa forma, antigos vínculos entre elas, ressaltando o caráter visual da escrita. Isso será registrado no diagrama, indicando e explorando as relações e entrecruzamentos entre palavra e imagem, através do seu diálogo cada vez mais íntimo na arte.

\section{Palavras-chave}

Continuidades, rupturas, cruzamentos e contaminações na gravura. Gravura no campo ampliado.

\begin{abstract}
The article proposes a discussion about printed art starting from a diagram of printing that moves from its genesis in nature, to its development into art in contemporary times. The diagram is structured based on the following factors: the anachronism of printing; continuities, ruptures, crossings and contaminations, and the extended field of printmaking. Among the rupture moments that most affected printmaking and printed art, the following are highlighted: the development of the press in the West; the invention and development of photography; the digital revolution / proliferation. The diagram also addresses the common principle of printing, word and image,
\end{abstract}


and their connection from prehistory to the Renaissance, when there is a first rupture between word and image, which will also affect printmaking. This word / image relationship will be resumed at the end of the 19th century and the beginning of the 20th century in the work of artists and poets who will explore this dialogue, often through graphic processes, diluting the hierarchy between word and image and thusly resuming old links between them and emphasizing the visual character of writing. This will be recorded in the diagram, indicating and exploring the relations and intercrossing between word and image, through its increasingly intimate dialogue in art.

\section{Keywords}

Continuities, ruptures, crossings and contamination in printmaking. Printmaking in the enlarged field.

\section{INTRODUÇÃO}

2 No original: "On emploi le verbe empreindre pour dire que l'on obtient une forme par pression sur ou dans quelque chose [...] Une connotation fréquente de l'empreinte - par différence avec la trace, peutêtre $[\ldots]$ - est que son résultat perdure, que son geste donne lieu a une "marque durable" (Didi-Huberman, 2008, p. 27).
Emprega-se o verbo imprimir para dizer que se obtém uma forma pela pressão sobre ou dentro de alguma coisa [...] Uma conotação frequente da impressão - pela diferença com o traço, talvez [...] - é que seu gesto perdura, que seu gesto dá lugar a uma "marca durável" (Didi-Huberman, 2008, p. 27, tradução minha)².

Nota-se que procedimentos de impressão são frequentes na arte contemporânea, abrangendo uma ampla gama de manifestações. Este artigo propõe uma discussão sobre a arte impressa, a partir de um diagrama (Figura 1) que aborda uma espécie de "memória da impressão", partindo da sua gênese na natureza e acompanhando o seu desenvolvimento na arte até a contemporaneidade. O diagrama parte das primeiras formas de impressão encontradas na natureza e, apesar de seguir uma ordem cronológica, possui inúmeras ramificações, que se comunicam entre si através de redes. Nele são explorados, em alguns momentos, continuidades, rupturas, cruzamentos e contaminações, entre obras de vários períodos históricos, que apontam para o anacronismo da impressão, tema que também será abordado.

O diagrama explora dois eixos principais, artes visuais e poesia, analisando de que maneira a estreita conexão existente desde os primórdios da civilização entre impressão, palavra e imagem neles se manifesta.

Partindo das impressões existentes na natureza, do lado direito do diagrama são apresentadas as origens da impressão escultórica, nas quais são geradas formas tridimensionais a partir da moldagem. $\bigcirc$ lado esquerdo traz exemplos da impressão pela gravação, raciocínio que possibilitaria o desenvolvimento da gravura em diferentes formas, com a introdução de dispositivos técnicos para a reprodução da imagem. Esse ramo específico da impressão será abordado neste trabalho, assim como seus desdobramentos.

Nesse texto o termo "arte impressa" será utilizado para se referir a diferentes formas de material impresso, incluindo a gravura. A escolha por esse termo justifica-se por abranger de uma forma ampla as manifestações artísticas atuais, que extrapolam, muitas vezes, os procedimentos tradicionais da gravura, abarcando um amplo leque de processos que envolvem material impresso, inclusive aquele preexistente.

Vários fatores e autores têm alimentado as pesquisas que a autora vem realizando sobre a arte impressa, e, dentre eles, destaca-se Georges Didi-Huberman (La ressemblance par contact. Archéologie, anachronisme et modernité de l'empreinte), com o qual este artigo estabelece um diálogo por entender que o livro citado traz uma inteligente e original abordagem da impressão, que contribui para seu estudo na arte contemporânea. 


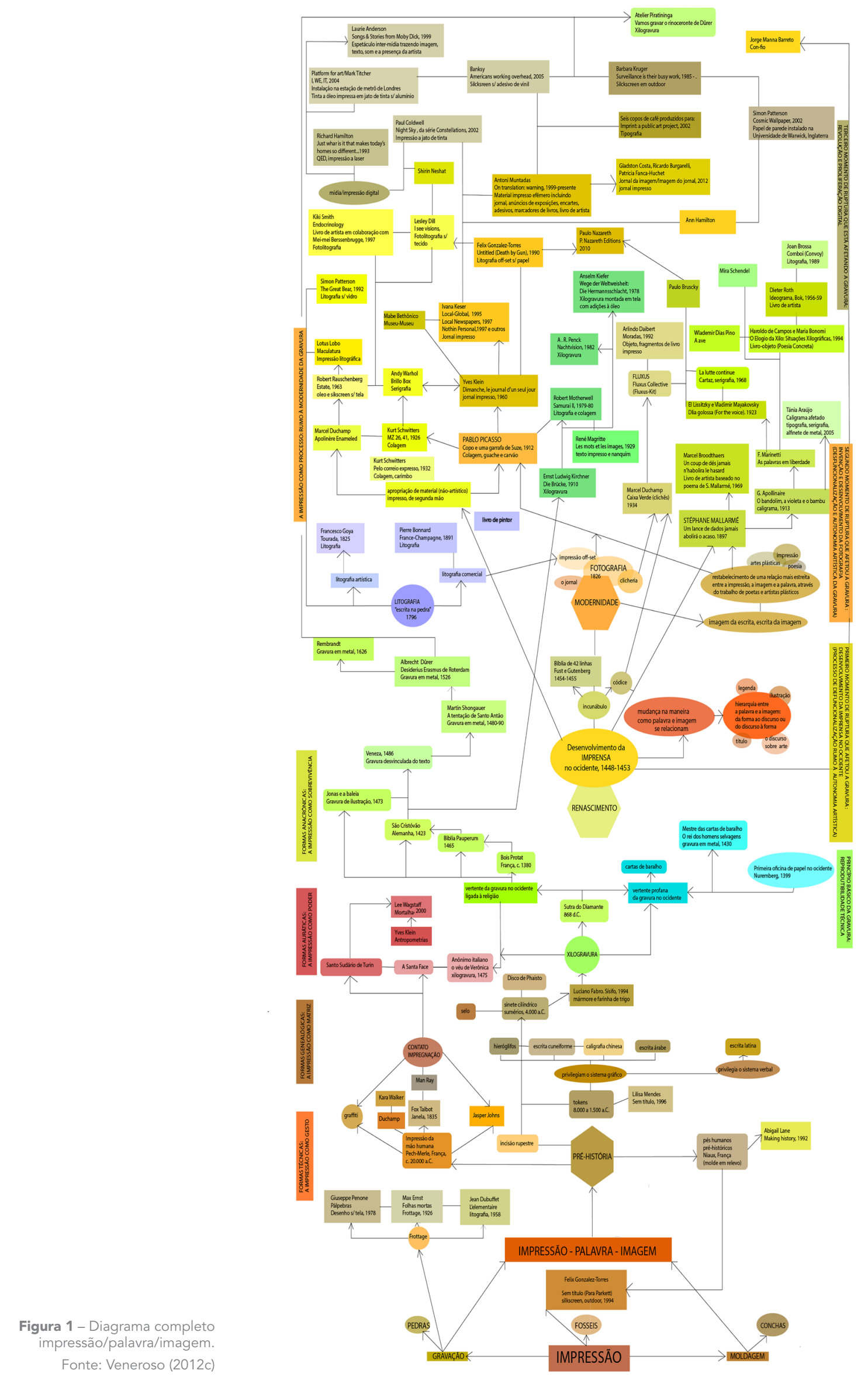


O diagrama apresentado tem início na pré-história com a impressão e se constrói a partir de três momentos de ruptura que afetaram a arte impressa e as relações palavra/imagem: Renascimento: desenvolvimento da imprensa no ocidente; Modernidade: invenção e desenvolvimento da fotografia; Contemporaneidade: revolução e proliferação digital.

Para começar, serão apontados alguns fatores que a autora considera importantes quando se discute a impressão e seus desdobramentos: o anacronismo da impressão; continuidades, rupturas, cruzamentos e contaminações e o campo ampliado da gravura (Veneroso, 2014).

\section{O ANACRONISMO DA IMPRESSÃO}

\begin{abstract}
É preciso, portanto, jogar [...] sobre os dois quadros do tempo: é a primeira exigência de um pensamento da impressão. Vamos nomeá-lo um ponto de vista anacrônico. Esse ponto de vista não é uma negação da história, bem o contrário. Mas devemos tomar nota do fato de que uma história da impressão não existe. Falta uma história para esse processo concreto que se dá como um savoir-faire de muito longa duração, aplicável a campos materiais e técnicas extremamente variadas; falta uma história para esse paradigma teórico que serviu de modelo a tantos pensamentos abstratos, especialmente quando se trata de pensar sobre noções tão fundamentais quanto aquelas do signo, do traço, da imagem, da semelhança, da genealogia; falta uma história para esse procedimento - ao mesmo tempo concreto e teórico - onde são definidas as escolhas formais e operatórias de tantos artistas, principalmente no século XX (Didi-Huberman, 2008, p. 12, grifos do autor, tradução minha) ${ }^{3}$.
\end{abstract}

Seguindo e desenvolvendo a mesma linha de pensamento de Didi-Huberman (2008), considera-se que a impressão é um gesto técnico e a técnica é uma estrutura do tempo, da memória, não somente do progresso. Muitos artistas do século $X X$ investiram e continuam a investir no século $X X I$, num campo operatório literalmente pré-histórico (fazer impressões), indicando caminhos para se pensar sobre a condição temporal da obra de arte moderna e contemporânea.

De acordo com esse raciocínio, pode-se dizer que as impressões produzidas pelos artistas contemporâneos não são particularmente arquetípicas, nem particularmente pós-modernas, formando um anacronismo fundamental que impõe o reconhecimento dos limites históricos geralmente em uso para falar das coisas ou sobre as coisas artísticas (Didi-Huberman, 2008).

\section{A IMPRESSÃO COMO GESTO}

Em todos os lugares impressões nos precedem ou nos seguem. Muitas nos escapam, muitas desaparecem, algumas vezes debaixo dos nossos olhos [...]. Muitas nos sobreviverão. Por mais numerosas que sejam, no entanto, podemos nos perguntar se elas chegam a formar um gênero, por diferirem umas das outras (Didi-Huberman, 2008, p. 11, tradução minha) ${ }^{4}$.

${ }^{4}$ No original: "Partout des empreintes nous prècédent ou bien nous suivent. Beaucoup nos échappent, beaucoup disparaissent, quelquefois sous nos yeux mêmes [... Beaucoup nous survivront Aussi innomblables soientelles, cependant, on peut se demander si elles forment bien un genre, tant elles diffèrent entre ells" (Didi-Huberman, 2008, p. 11)
Obras de arte contemporânea apontam para o anacronismo da impressão ao utilizarem procedimentos tão rudimentares como um gesto, como a marca dos passos humanos na areia da praia, presente no outdoor impresso em serigrafia Untitled (for Parkett) de 1994, de Félix Gonzalez-Torres. Trata-se de um trabalho que pode ser aproximado da imagem de pegadas humanas; uma moldagem em relevo na caverna de Nioux na França (entre 30.000 e 10.000 anos a.C.) que remete a um marco da evolução humana, de um gesto remoto da verticalização do homem (Didi-Huberman, 2008). O que aproxima os dois atos é o fato de que forma e contraforma se reúnem em um mesmo dispositivo, remetendo à presença e à ausência de quem as fez e, assim, à identidade do sujeito (Figura 2). 


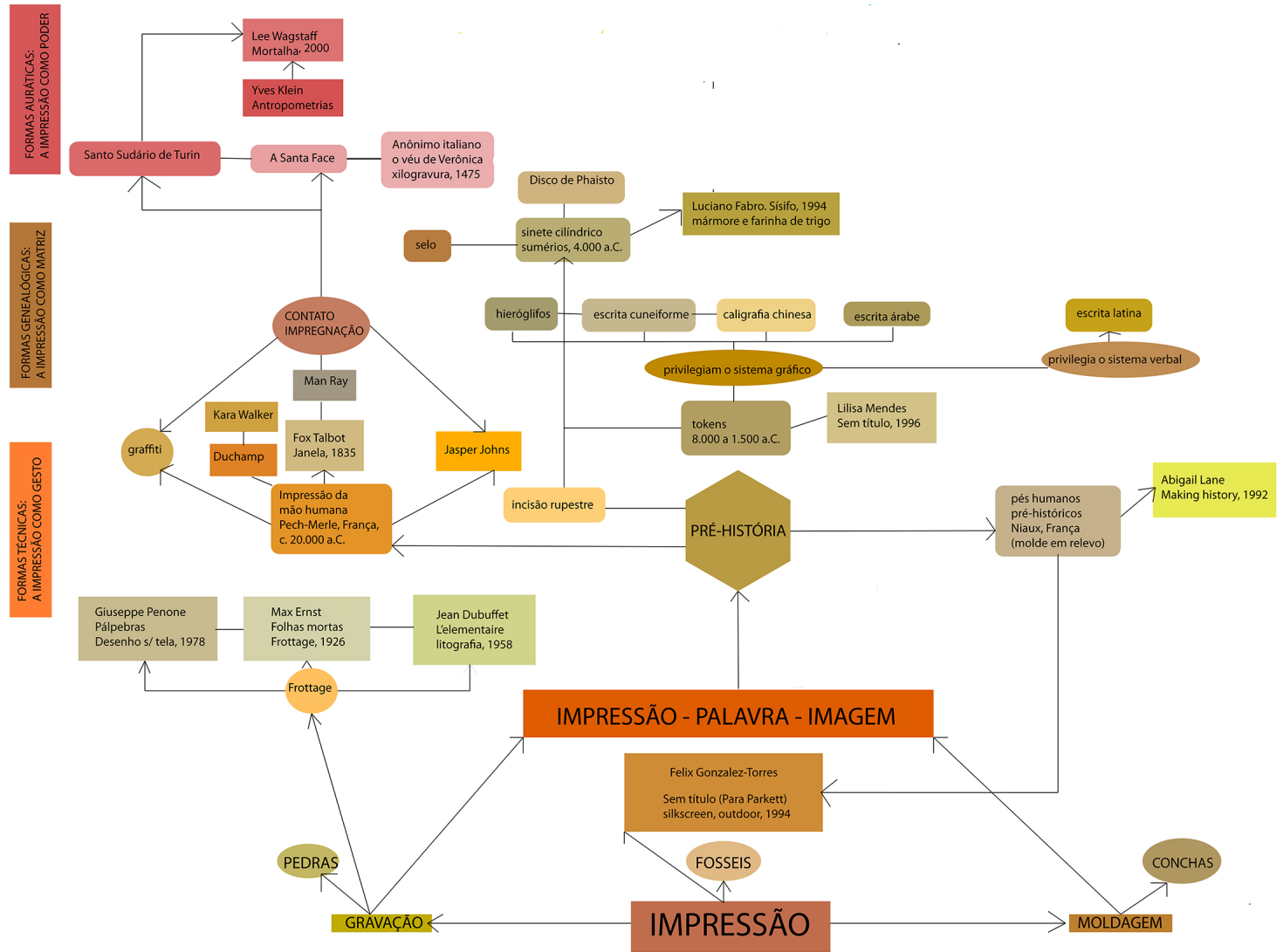

Figura 2 - Detalhe 1 do diagrama impressão/palavra/ imagem.

Fonte: Veneroso (2012c)
5 No original: Tuchè et techné: I'histoire de l'art ancient est pleine des drames et des réussites magiques qu'engendrèrent leurs rencontres. De ces rencontres, l'empreinte se fait un principe, qui aboutit au non-principe suivant: on ne sait jamais exactement ce que cela va donner (Didi-Huberman, 2008 p. 33).
Também certos artistas, a partir do uso do frottage, como nas obras L'elementaire, de Jean Dubuffet; Pálpebras, de Giuseppe Penone e Folhas mortas, de Max Ernst, podem ser considerados "arqueólogos da semelhança" e dos "anacronismos" da impressão. Eles se apropriam de formas da própria natureza, ressignificando-as a partir da impressão, assim como Leonardo da Vinci que via, nas manchas da parede, nas nuvens, na correnteza da água, "coisas maravilhosas" das quais ele se apossava para criar composições como lutas de homens e animais, paisagens, monstros, demônios e outras coisas fantásticas. Em L'elementaire, Dubuffet registra as nervuras e detalhes de folhas secas através do frottage em papel transporte, gerando uma imagem transferida em seguida para a pedra litográfica, matriz a partir da qual ela seria impressa. Na obra Pálpebras, Penone passou grafite em pó sobre suas pálpebras fechadas, imprimindo-as em seguida sobre papel através de frottage. A imagem produzida foi fotografada por meio de slides projetados sobre uma tela branca, que geraram desenhos a carvão, dando a ver o negativo das pálpebras em uma escala macro.

Nos dois casos expostos, trata-se de procedimentos de impressão que passam por diversas etapas, através das quais os artistas reproduzem, finalmente, as imagens registradas. Assim, através de um processo de impressão rudimentar como o frottage, os artistas realizam trabalhos muito elaborados, explorando vários processos de impressão, arcaicos e modernos, em uma mesma obra, gerando novos significados.

\section{A IMPRESSÃO POR CONTATO E IMPREGNAÇÃO}

Tuchè e technè: a história da arte antiga está cheia de dramas e de sucessos mágicos que engendraram seus encontros. Desses encontros, a impressão se faz um princípio, que resulta no anti-princípio seguinte: não se sabe jamais exatamente no que isso vai resultar (Didi-Huberman, 2008, p. 33, grifos do autor, tradução minha) ${ }^{5}$. 
Observando a mão na parede da caverna, percebe-se a existência de uma íntima relação entre o processo utilizado pelo homem pré-histórico para imprimi-la e o processo usado por artistas contemporâneos nos seus trabalhos, apontando mais uma vez para o anacronismo da impressão. A mão pré-histórica foi utilizada como um molde para a sua impressão, e esse procedimento pode ser aproximado do estêncil vazado, que vem sendo muito usado no grafite e na arte urbana (Veneroso, 2012b). Ambos os procedimentos apontam para o raciocínio da impressão através do contato e da impregnação (Didi-Huberman, 2008). E essa aproximação, como muitas outras, atesta que a impressão é um procedimento atemporal.

O Santo Sudário utiliza a impressão por contato, procedimento que tem sido usado também em obras de artistas contemporâneos, entre elas as antropometrias de Yves Klein e no autorretrato Mortalha, de Lee Wagstaff, obra na qual foi usado o corpo do artista, coberto de tatuagens, com motivos e padrões criados por ele. Enquanto o artista era tatuado, os panos utilizados na absorção do sangue foram impressos com as mesmas formas tatuadas. A partir disso Wagstaff executou uma serigrafia, partindo da fotografia do seu corpo, em escala 1:1. A obra impressa com pigmento oriundo do seu próprio sangue, que carrega o DNA do artista, comprova, de certa forma, a "autenticidade" da gravura da mesma forma que o sudário de Cristo é referido como uma prova física da sua existência na terra (Veneroso, 2012b).

\section{CONTINUIDADES, RUPTURAS, CRUZAMENTOS E CONTAMINAÇÕES}

${ }^{6}$ No original: "On ne peut rien comprendre à une technique - donc à un art - si on ne cherche pas à dégager quelque chose de sa dimension anthropologique [...] Parce que faire une empreinte, c'est toujours produire un tissu de relations matérielles qui donnent lieu à un objet concret (par exemple une image estampé), mais qui engagent aussi tout un ensemble de relations abstraires, mythes, fantasmes, connaissances, etc." (Didi-Huberman, 2008, p. 32)
Não se pode compreender nada de uma técnica - portanto de uma arte - se não procurarmos esclarecer alguma coisa da sua dimensão antropológica [...] Porque fazer uma impressão é sempre produzir um tecido de relações materiais que dão lugar a um objeto concreto (por exemplo uma imagem estampada), mas que engajam também todo um grupo de relações abstratas, mitos, fantasmas, conhecimentos, etc. (Didi-Huberman, 2008, p. 32, grifos do autor, tradução minha) ${ }^{6}$

Para que seja possível perceber as rupturas, precisa-se de tempo, ou seja, de distanciamento. Alguns momentos de ruptura afetaram profundamente a gravura e a arte impressa em geral: o desenvolvimento da imprensa no ocidente; a invenção e o desenvolvimento da fotografia; a revolução/ proliferação digital.

No mundo chinês, a palavra "impressão" abarca duas técnicas que são, de fato, bastante diferentes - xilogravura e tipografia. Mas enquanto na China e na Ásia oriental a primeira gozou de uma difusão ilimitada e a última teve um alcance restrito, na Europa ocorreu o fenômeno contrário. Enquanto a xilogravura teve uma difusão limitada, a imprensa provocou uma verdadeira revolução. As primeiras xilogravuras surgiram na China entre o final do século VII e o início do século VIII; porém, só em meados do século $X$ a reprodução da palavra escrita, através de textos mais longos, começou a ser praticada por meio desse processo (Figura 3).

Já os registros do surgimento da gravura no ocidente apontam para o final do século XIV, sendo que a abertura da primeira oficina de papel no ocidente, em Nuremberg, em 1399, muito contribuiu para o seu aparecimento e difusão. A xilogravura religiosa dá início a uma linhagem a partir de obras como a Bois Protat, que se desdobraria em inúmeras outras. Num período em que a reprodutibilidade da gravura era fundamental, pois ainda não existiam outros meios para se reproduzir textos e imagens, ela se popularizou rapidamente no seu papel de levar o conhecimento até a sociedade, em grande parte iletrada. Assim, era através de xilogravuras que traziam textos e imagens que a doutrina religiosa era difundida. 
Figura 3 - Detalhe 2 do diagrama impressão/palavra/ imagem.

Fonte: Veneroso (2012c)

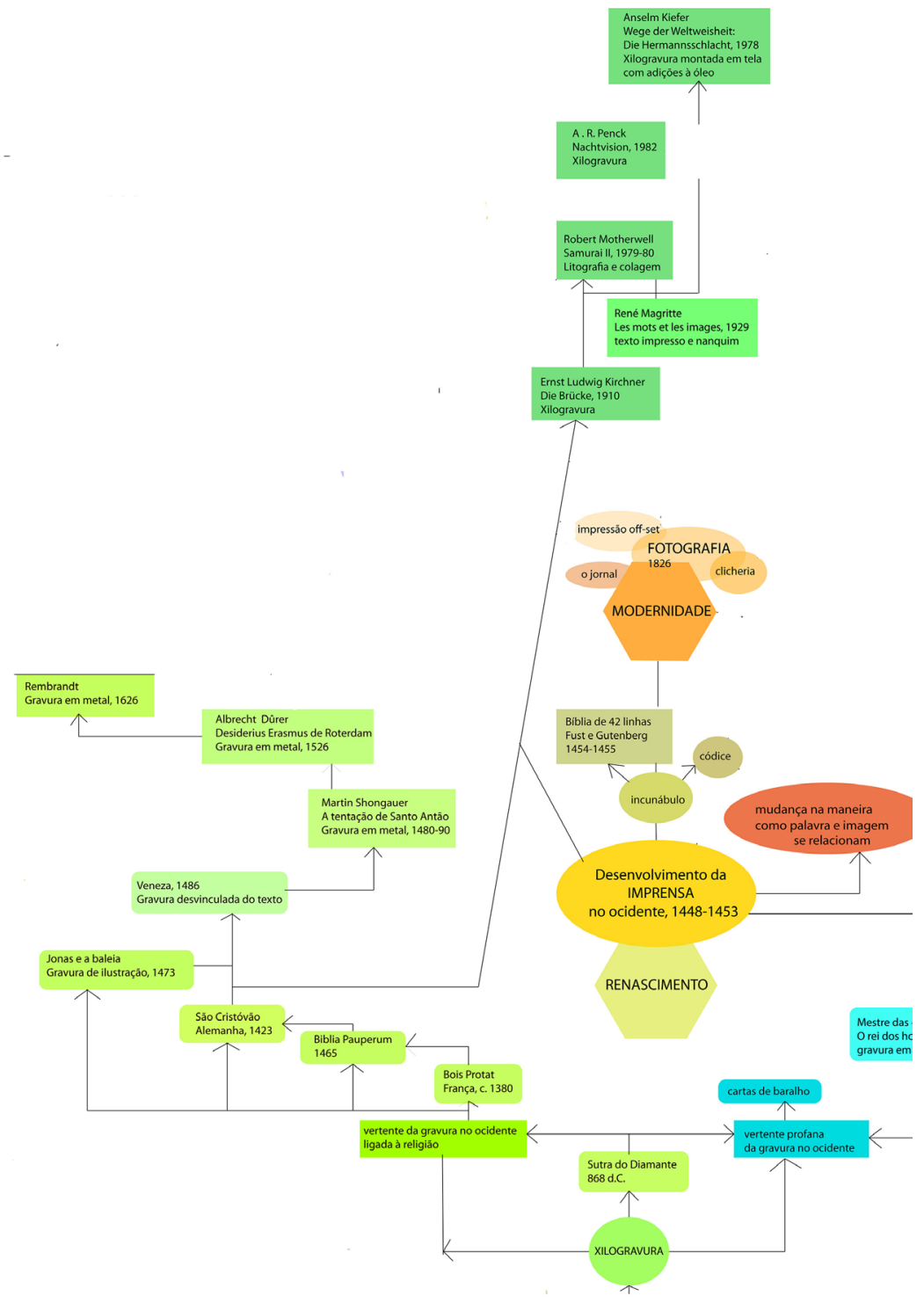

Com o surgimento da imprensa, que permitiu a reprodutibilidade do texto impresso através dos tipos móveis, possibilitando a difusão do saber por meio dos livros impressos, e com o fim dos manuscritos medievais, um novo uso foi dado à gravura: a ilustração dos textos, substituindo as iluminuras. Isso provocou uma ruptura, pois, como consequência disso, um novo tipo de vínculo se estabeleceu entre imagem e texto, já que as ilustrações estabeleceram uma relação de dependência com o texto impresso, se prestando a traduzi-lo em termos de formas e cores. Passa a prevalecer, pois, uma relação hierárquica entre o texto e a imagem, que vai da forma ao discurso, ou do discurso à forma, através da legenda, do título, do discurso sobre arte e principalmente através da ilustração. Assim, se anteriormente palavra e imagem relacionavam-se nas gravuras sem seguir necessariamente uma relação hierárquica, nos livros, a ilustração, a princípio realizada em xilogravura ou gravura em metal, depende do texto para existir. Esse diálogo entre palavra e imagem passará por inúmeras modificações, sendo que a relação hierárquica entre elas será um ponto de tensão, pois em alguns momentos a palavra ou a imagem terá precedência uma sobre a outra. Essa discussão será retomada neste texto oportunamente.

Assim, se a gravura, ao surgir, tinha uma função, que era a de divulgar imagens múltiplas, associadas na maior parte das vezes a textos, com o 
${ }^{7}$ No original: "Il eût été, en particulier, fort trompeur de renvoyer l'empreinte au pur passé d'une condition pré historique de l'image (que cette condition soit ressentie comme obscurantiste ou comme paradisiaque); et non moins trompeur de "bloquer" l'empreintedans le présent faussement spécifique, fausement définitif dur définitif, d'une condition moderne, voire "postmoderne", des arts visuels" (Didi-Huberman, 2008, p. 11) surgimento dos tipos móveis a gravura se desvincula do texto, passando a existir como uma entidade independente, se direcionando no sentido de adquirir autonomia artística. Executada a princípio por artesãos anônimos, mais tarde a gravura ganha status artístico, assinada por artistas como Dürer, Rembrandt e Goya, cujo trabalho se desdobraria em uma linhagem de gravadores como os expressionistas alemães, como Ernst Ludwig Kirchner, tendo continuidade no expressionismo abstrato com Robert Motherwell e outros, até sua retomada no neo-expressionismo com artistas como Anselm Kiefer e A. R. Penk. Todos eles pertencem a uma tradição da gravura de tendência expressionista que vem se desenvolvendo desde o século XIV até o presente, apresentando uma parcela importante da gravura produzida nesse período.

No desenvolvimento da gravura no ocidente, a descoberta de um novo processo de impressão, a litografia, no final do século XVIII, inauguraria uma nova era com a produção de material gráfico industrial de qualidade e que supriria uma demanda existente por rótulos, mapas, revistas e cartazes numa época em que a necessidade por esse tipo de material gráfico era crescente em função da industrialização. Paralelamente a essa produção comercial/industrial, a litografia logo seria utilizada também por inúmeros artistas que buscavam, com essa técnica, produzir estampas e cores em grandes tiragens.

Um segundo momento de ruptura que afetaria a gravura foi desencadeado a partir da invenção da fotografia, que revolucionaria os impressos. Os processos gráficos de impressão se modificaram com a incorporação de processos fotográficos, que tomariam o lugar antes ocupado pela litografia comercial, pela tipografia e pela clicheria. Esses processos seriam aos poucos substituídos por processos fotográficos industriais, levando a gravura a perder, gradativamente, sua função comercial. Tudo isso levou os processos obsoletos da gravura comercial a serem apropriados pela gravura artística, que continua até hoje a se contaminar dessa sua vocação comercial. Um exemplo emblemático disso é o trabalho de Lotus Lobo, artista e pesquisadora que utiliza em sua obra antigas marcas da estamparia litográfica, dando novos significados a elas. Paralelamente, Lotus desenvolve também um trabalho de preservação das marcas, como um patrimônio que diz muito sobre a história da gravura e do design.

Concluindo, quando a gravura perde suas funções comerciais e industriais, ela reafirma a sua função artística. Com o aparecimento de novos meios de reprodução da imagem, a capacidade de reproduzir imagens a partir da gravura passa a não ser tão relevante. Muitos artistas passam, então, a trabalhar com cópias únicas e isso expandirá o campo da gravura, que passará a explorar vínculos com outros meios, entre eles a fotografia, a pintura e a escultura, além de retomar seu vínculo arcaico com a escrita (Veneroso, 2012b).

\section{O CAMPO AMPLIADO DA GRAVURA}

Teria sido, em particular, muito enganoso reenviar a impressão ao puro passado de uma condição pré-histórica da imagem (quer essa condição seja sentida como obscurantista ou paradisíaca); e não menos enganoso "bloquear" a impressão em um presente falsamente específico, falsamente definitivo, de uma condição moderna, mesmo "pós-moderna", das artes visuais (Didi-Huberman, 2008, p. 11, grifos do autor, tradução minha) ${ }^{7}$.

Com a ampliação do seu campo, a gravura passa a estabelecer, cada vez mais, diálogos com outras linguagens. Um desses diálogos se dá com a palavra escrita numa espécie de retomada de relações pré-existentes entre impressão/palavra/imagem. 
Retornando ao diagrama da Figura 2 e acompanhando os processos de impressão, nota-se que desde que o homem produziu as primeiras formas nas paredes das cavernas o raciocínio da impressão já estava presente através de incisões rupestres ou da impressão, por contato e impregnação, das suas próprias mãos na superfície parietal. O homem pré-histórico se comunicava através de gestos, sons e nós, mas também através de signos, marcas e sinais que podem ser interpretados, semiologicamente, como uma espécie de "escrita". Essas relações entre a escrita, a imagem e a impressão se desdobraram desde a arte rupestre, passando pela escrita cuneiforme, gravada na argila pelos hieróglifos egípcios e gravados na pedra pelos diferentes alfabetos e caracteres da escrita ideogramática, sendo que todos eles possuem um evidente caráter icônico na sua origem.

A incisão rupestre se desdobrou em inúmeras formas de proto-escrita e de escrita que podem ser aproximadas de obras de artistas contemporâneos. Um exemplo disso é Sísifo, de 1994, de Luciano Fabro, na qual o artista utiliza uma peça de mármore gravada com incisões para imprimir sobre uma camada de farinha de trigo, remetendo às impressões com sinetes cilíndricos sumérios que traziam caracteres entalhados em baixo relevo, utilizados para selar envelopes de argila que continham correspondências escritas pelos escribas, autenticando o documento.

Já o artista chinês Xu Bing usa como referência a tradicional impressão em bloco chinesa e o formato do rolo na instalação Um livro do céu (1987-1991). Bing cresceu sob o regime de Mao Tse Tung, onde "palavras sozinhas poderiam determinar o destino de uma pessoa" (Morley, 2003, p. 194). Naquele sistema político repressivo, textos escritos eram altamente valorizados e rigorosamente controlados, e desempenhavam um papel dominante na propaganda. $O$ artista conviveu na infância com grandes caracteres da escrita chinesa, indo do céu ao chão em cartazes e slogans que se espalhavam nas ruas. Essas referências foram por ele utilizadas ao criar, anos mais tarde, uma escrita chinesa falsa, impressa em rolos a partir de blocos de madeira, na instalação citada acima.

Partindo da história da escrita, é possível perceber que os estreitos vínculos existentes entre a imagem, a escrita e a impressão desde a pré-história, perduraram no ocidente até o final da Idade Média em obras como a Biblia Pauperum, xilogravura executada por um artesão anônimo em 1465, na qual palavras e imagens, gravadas na mesma placa de madeira, se relacionam não hierarquicamente. A partir do Renascimento, com o surgimento da imprensa no ocidente, há uma mudança na maneira como palavras, imagens e o impresso se relacionam, passando a obedecer a uma espécie de hierarquia, indo do discurso à forma por meio das ilustrações dos textos impressos, como já foi mencionado.

Essa relação hierárquica vai se diluindo, e a partir das últimas décadas do século XIX e primeiros anos do século XX, conexões mais profundas entre escrita e imagem vão ser restabelecidas por artistas visuais e poetas num lugar fronteiriço, limítrofe, em que a imagem e a letra se encontram, reatando os antigos vínculos entre palavra e imagem. Assim, ao mesmo tempo em que poetas exploram a visualidade da letra, as palavras surgem na tela, retomando a sua iconicidade.

Pode-se apontar o surgimento de duas linhagens de artistas e poetas a partir de Mallarmé e Picasso, e a maneira como eles tratam as relações entre palavra e imagem, através de procedimentos de impressão, será desenvolvida a seguir.

\section{MALLARMÉ, APOLLINAIRE, MARINETTI, EL LISSISTKY E VLADIMIR MAIAKOVSKI, MARCEL BROODTHAERS, DIETHER ROTH, WOLF VOSTELL, FLUXUS, JOAN BROSSA, PAULO BRUSCKY, HAROLDO DE CAMPOS E MARIA BONOMI}

O poema Um lance de dados jamais abolirá o acaso, de Stéphane Mallarmé, provoca uma grande mudança na poesia ao ser composto a 
8 No original: "Si faire une empreinte n'est en général rien d'autre que "bricoler" une relation entre un corps et un substrait, alos il faut rendre au bricolage la haute valeur anthropologique et valér anthropologique et gnoséologique qu'il occupe préciséement dans le yexte de Lévi-Strauss. Toutes les caractéristiques que celui cireconnaît au bricolage se retrouvent dans le geste de l'empreinte: le principe non orienté du "ça peut toujours servir"; I'ouverture au "mouvement incident", au hasard technique, à "I'absense du project"; mais aussi à la possibilité de "résultats brillants et imprévus" (Didi-Huberman, 2008, p. 32). partir de processos visuais, apontando para uma tomada de consciência da visualidade dos signos linguísticos e do espaço da página como elementos constituintes do poema (Veneroso 2012a). Porém, as raízes para essa poesia, que passa a ser praticada no final do século XIX, podem ser localizadas na Antiguidade Helenística, com poetas que exploram a visualidade da letra e o espaço vazio da página como partes estruturantes do poema. Considera-se o poeta Simias de Rhodes (século IV a.C.) como o autor dos primeiros versos figurados. Nesses poemas o comprimento variável das linhas é combinado com a restrição linear do alfabeto, mostrando a forma do objeto que dá título ao poema, no decorrer da sua leitura (Christin, 2002). Seu poema, O Machado, foi traduzido para o francês e impresso em tipografia entre 1772 e 1776, época em que houve um interesse acentuado por esses artifícios devido ao desenvolvimento dos tipos móveis, que criaram a oportunidade para que ocorressem experimentos como esse. 0 poema figurado em forma de garrafa de vinho, o Dive Bouteille, atribuído a Rabelais, foi um dos seus desdobramentos.

Pode-se citar, também, a Carmina Figurata, de Rabanus Maurus, do início do século IX, como pertencente a essa linhagem de poemas. Essa obra joga com o alinhamento das letras para formar figuras e também para glorificar o valor esotérico da mensagem transmitida.

No século $\mathrm{XV}$, a submissão das letras a moldes tipográficos abalaria a tradição dos hábitos adquiridos com a escrita à mão, na qual cada letra era conectada à sua vizinha por uma rede de ligações. Os autores, ao se conscientizarem das novas possibilidades da impressão a partir de tipos móveis, passaram a explorar diversas configurações para o texto, como Aldus Manutius ao imprimir o texto Hypnerotomachia Poliphili (O sonho de Poliphilo), de Francesco Collona, em 1499. Essa tendência seria retomada em 1760 por Laurence Sterne em um experimento literário original chamado Tristan Shandy (Christin, 2002) (Figura 4).

Essa tendência no Ocidente de uma literatura privilegiando o aspecto visual do texto, confirmada pela publicação de Um lance de dados (1897-1914), teria sequência no trabalho de poetas como Guillaume Apollinaire, com seus Caligramas de 1918. Esses poemas revivem a tradição dos versos figurados, inspirados também pelo trabalho de Marinetti, As palavras em liberdade, seguidos, entre outros, por El Lissitzky, com Dia glossa, realizado em parceria com Vladimir Vladimir Maiakovski em 1923. Esses experimentos literários e visuais tiveram continuidade por todo o século $X X$, com destaque para o movimento letrista, a poesia concreta e para os livres de peintre, nos quais textos e imagens interagem, além dos cartazes do Atelier Populaire, na França, e dos poetas e artistas Marcel Broodthaers, Diether Roth, Joan Brossa, além do brasileiro Wlademir Dias Pino, entre outros.

\section{PICASSO, KURT SCHWITTERS, MARCEL DUCHAMP, YVES KLEIN, ROBERT RAUSCHENBERG, ANDY WARHOL, LOTUS LOBO}

\begin{abstract}
Se fazer uma impressão não é em geral nada mais que "bricolar" uma relação entre um corpo e um substrato, então é preciso dar à bricolagem o alto valor antropológico e gnoseológico que ele ocupa precisamente no texto de Lévi-Strauss. Todas as características que este reconhece na bricolagem se encontram no gesto da impressão: o princípio não orientado de "isso pode sempre servir"; a abertura ao "movimento incidental", ao acaso técnico, à "falta de projeto"; mas também à possibilidade de "resultados brilhantes e imprevistos" (Didi-Huberman, 2008, p. 32, tradução minha) ${ }^{8}$.
\end{abstract}

Paralelamente a esse movimento na poesia da exploração da visualidade da letra, acontece um movimento análogo nas artes visuais (Figura 5). Esse movimento dá início a uma vertente que também se vincula ao 


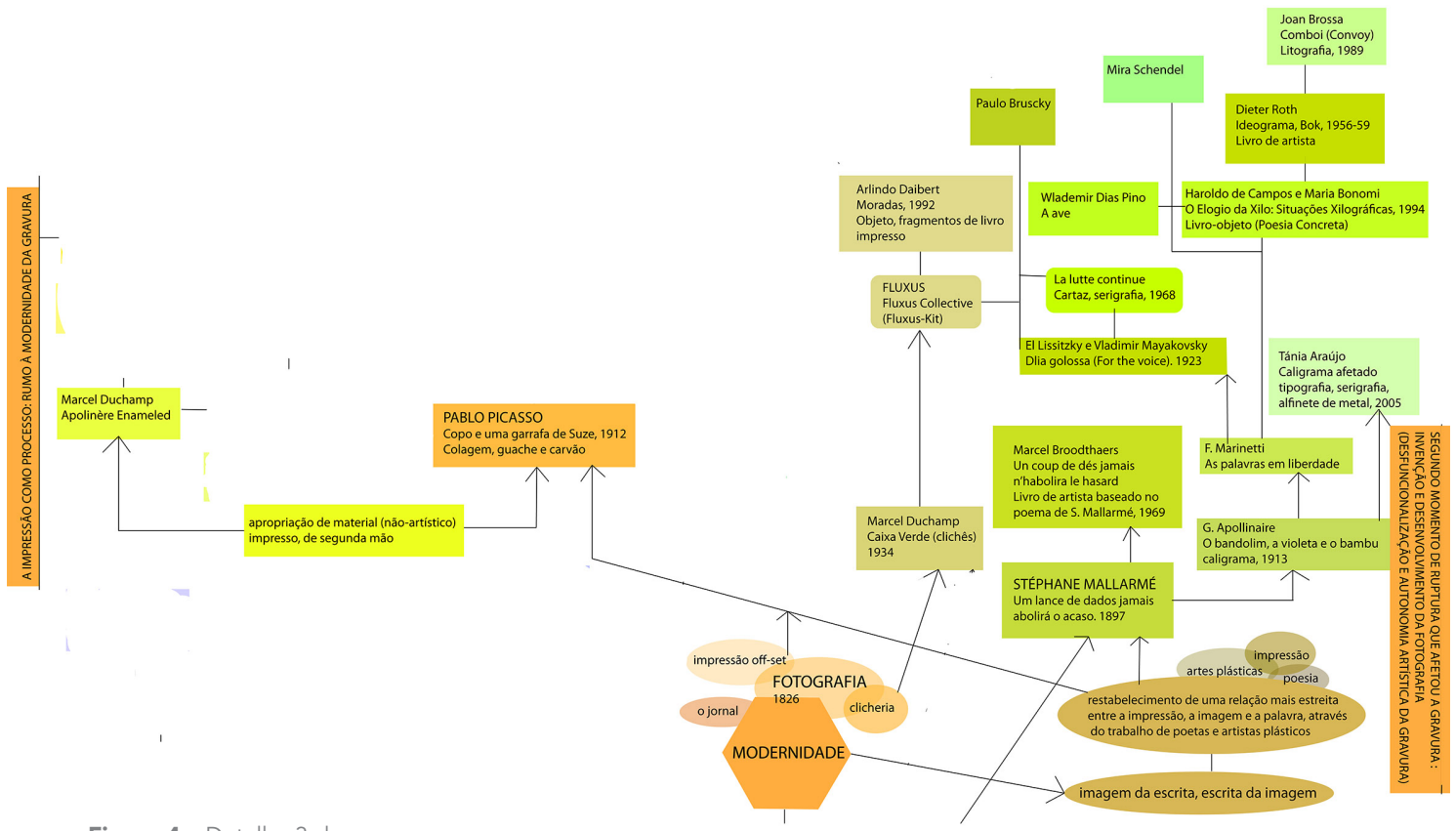

Figura 4 - Detalhe 3 do diagrama impressão/palavra/

Fonte: Veneroso (2012c)

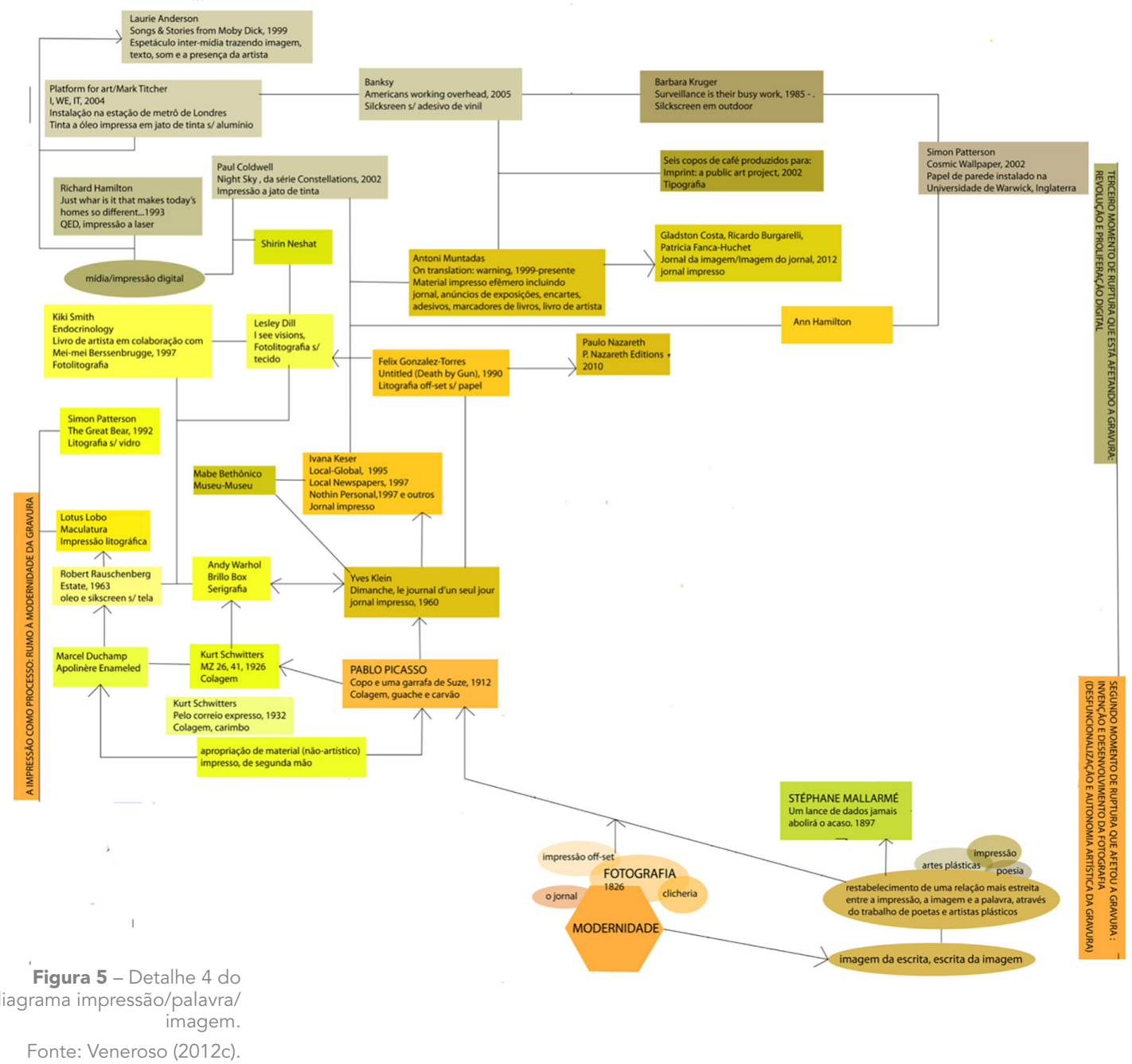


desenvolvimento da imprensa no Ocidente e à fotografia, e foi iniciado por artistas que trabalham com o texto visual a partir da apropriação de materiais não artísticos impressos de segunda mão. Assim o refugo gerado pela produção gráfica comercial e industrial, como textos tipográficos, embalagens, bilhetes de trem e partituras musicais, passou a ser utilizado por vários artistas, dando origem a uma forte tendência das artes do século XX que está presente desde o Cubismo nos papiers collés de Picasso e Braque e nas colagens de Kurt Schwitters. Dentre os artistas que pertencem a esse grupo, encontra-se, sem dúvida, Marcel Duchamp, com seus ready-mades, destacando-se a obra L.H.O.O.Q., de 1919.

A gravura artística havia trilhado seu caminho sem alterações significativas até as décadas de 1960 e 1970, quando as técnicas e imagens gráficas invadiram o mundo artístico. Foi quando os artistas começaram a associar as técnicas tradicionais da gravura artística com outras baseadas na reprodução fotográfica e outros meios já usados comercialmente. A Pop Art é um momento especialmente fecundo nesse contexto, com inúmeros desdobramentos. Podem ser ressaltados os trabalhos emblemáticos tanto de Rauschenberg quanto de Warhol, que revolucionariam a gravura por introduzirem o uso de processos fotomecânicos, a apropriação de imagens e textos pré-existentes e também a criação de cópias únicas onde a gravura é combinada com outras linguagens, como a pintura. Robert Motherwell também se apropria de marcas e rótulos pré-existentes em suas gravuras. Artistas do Nouveau Realisme, como Yves Klein, com o jornal impresso Dimanche, le journal d'un seul jour, de 1960; Wolf Vostell com as suas décollages e o letrista Mimmo Rotella darão sequência a essa tendência na arte, que continua a reverberar até hoje no trabalho de vários artistas como Ivana Keser, com jornais impressos como Local-Global de 1995, e Felix Gonzalez-Torres, que também se apropria, entre outras coisas, do jornal impresso como veículo para seus trabalhos.

A contaminação da gravura por processos comerciais de impressão é visto frequentemente nos trabalhos dos artistas. Isso envolve o cartaz de rua, o jornal diário, a publicidade e os outdoors, apontando para as relações entre gravura artística e gravura comercial, mostrando que esse diálogo persiste, e que, talvez, a contaminação e a impureza sejam características inerentes à arte impressa. Assim sendo, não é nem mesmo desejável a busca por uma pureza dos meios gráficos. Essa impureza da gravura e sua contaminação por outros meios vêm sendo explorada por vários artistas, como o Grupo Poro, com seus azulejos impressos em ofsete comercial, além de cartazes, stickers, gravuras lambe-lambe, de Paulo Nazareth, que utiliza volantes impressos em ofsete comercial para veicular seu trabalho.

Outro ponto a ser enfatizado é que os papiers-collés de Picasso e o poema Um lance de dados, de Mallarmé, inauguraram uma nova visualidade da letra e da página/tela, que se estenderia por todo o século $X X$, tendo continuidade no século XXI no trabalho de artistas e poetas como Paulo Bruscky, Simon Patterson, Barbara Kruger, Jenny Holzer, Lesley Dill, Kiki Smith e Paul Coldwell. É interessante notar que essas duas linhagens, de poetas e de artistas, estão cada vez mais próximas, mostrando que, na arte atual, o trânsito entre as linguagens é cada vez maior e isso se reflete também nas relações entre palavra e imagem.

\section{CONSIDERAÇÕES FINAIS}

Observa-se que um terceiro momento de ruptura tem afetado a arte impressa nos últimos anos: a revolução e proliferação digital (Figura 6). Assim, as tecnologias digitais vêm sendo incorporadas, cada vez mais, à arte impressa, dando origem a trabalhos instigantes que vêm ampliando o significado e o alcance da gravura e da arte impressa. Assim, ambas englobam hoje vários tipos de impressão, desde aquelas obtidas através 


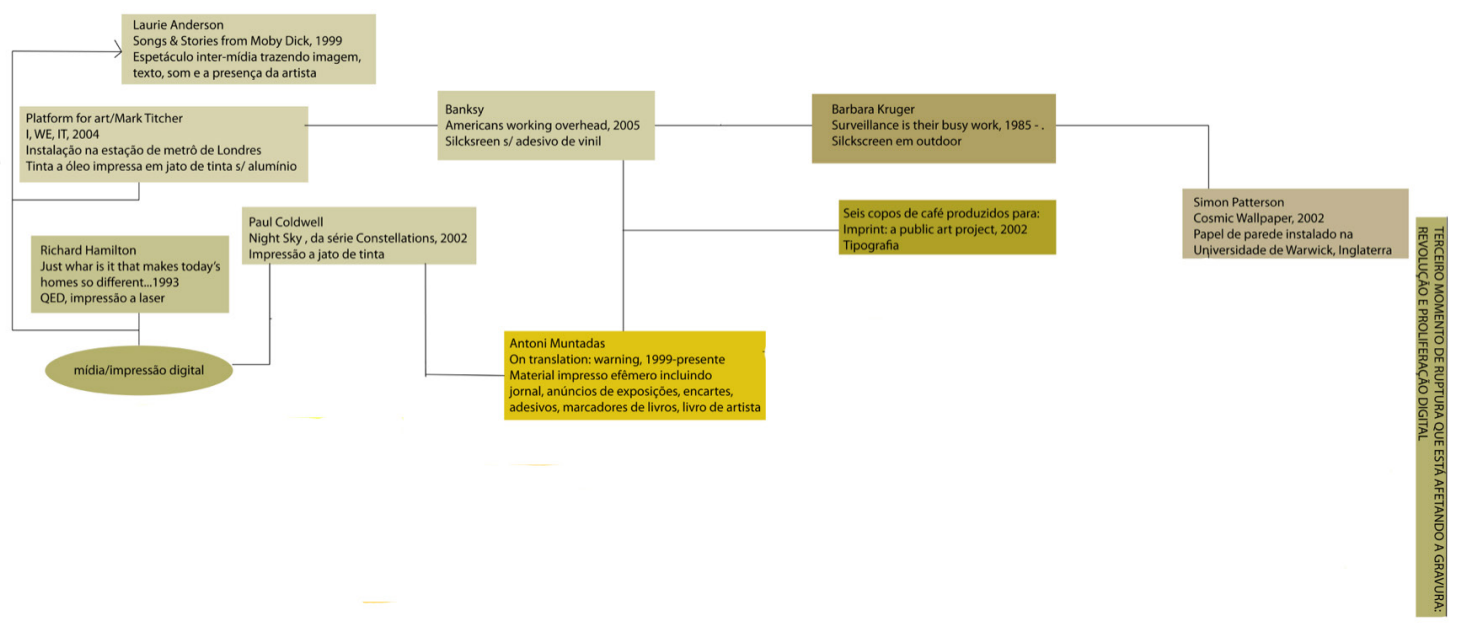

Figura 6 - Detalhe 5 do diagrama impressão/palavra/ Fonte: Veneroso (2012c) dos processos tradicionais de gravura, passando pelos processos comerciais, até as tecnologias digitais, gerando também obras híbridas que podem incluir ainda desenho, escultura e fotografia na combinação de vários processos.

O público e o mercado para gravuras transformaram-se radicalmente nos últimos anos. Muitos artistas ainda trabalham com edições impressas uniformemente, mas muitas gravuras contemporâneas circulam fora dessa estrutura, incluindo as autopublicações, que criam um mercado alternativo. Há artistas criando obras únicas e, paralelamente, têm surgido edições ilimitadas e sem numeração. Têm sido realizadas também adaptações da gravura para projetos site-specific, como em trabalhos de Regina Silveira e Mônica Nador. A Internet tem dado origem a trabalhos nos quais há a possibilidade de colaborar online com o artista. Paralelamente, continua a existir em alguns países a tradição de artistas trabalhando em ateliês especializados em gravura, que oferecem a infraestrutura para a sua prática.

Como já foi discutido, pode-se considerar que a impressão é anacrônica, não pertencendo a um tempo da História da Arte. Já a gravura permite que se trace a sua história, pois é possível identificar sua gênese e seu desenvolvimento temporal. A partir de todas as colocações apresentadas neste artigo, pode-se, finalmente, perguntar quais seriam as relações da gravura com a História da Arte, pois nota-se que ela, de certa maneira, não se insere nessa história. Percebe-se que a impressão, e mais tarde, a gravura, sempre foram pensadas a partir de seus aspectos técnicos, sendo perceptível o impacto que as grandes revoluções técnicas exerceram sobre a gravura. Nota-se que as publicações sobre gravura costumam enfatizar muito mais uma história da técnica do que uma história das imagens na gravura. É, pois, relevante pensar no papel que a técnica desempenha na história da gravura. A presença de registros técnicos preservados, da impressão dos primórdios da humanidade, indica que a impressão é central na história da humanidade. A técnica é também fundamental na gravura - tratando-se de uma linguagem do métier -, que possui um knowhow próprio. Assim, talvez a história da gravura possa ser contada a partir das suas técnicas. Provavelmente tenha sido justamente essa ênfase nos aspectos técnicos, inerentes à gravura, que tenha se tornado um fator determinante para que a gravura se mantivesse marginalizada em relação às outras artes, e porque não dizer, em relação à própria História da Arte.

\section{REFERÊNCIAS}

Christin, A. M. (org.). A history of writing: from hieroglyph to multimedia. Paris: Flammarion, 2002. 
Didi-Huberman, G. La ressemblance par contact: archéologie, anachronisme et modernité de l'empreinte. Paris: Minuit, 2008.

Morley, S. Writing on the wall: Word and image in modern art. Berkeley: University of California Press, 2003.

Veneroso, M. C. F. Caligrafias e escrituras: diálogo e intertexto no processo escritural nas artes no século XX. Belo Horizonte: C/Arte, 2012a.

Veneroso, M. C. F. O campo ampliado da gravura: suas interseções e contrapontos com a escrita e a imagem no contexto da arte contemporânea. Revista Porto Arte, v. 32, p. 85-102 2012b.

Veneroso, M. C. F. Diagrama completo impressão/palavra/imagem. Belo Horizonte: [s. n.], 2012c. Disponível em: http://diagrama.cacaufreitas.com/1/. Acesso em: 20 out. 2020.

Veneroso, M. C. F. O campo ampliado da gravura: continuidades, rupturas, cruzamentos e contaminações. Art Research Journal, v. 1, n. 1, p. 171-183, 2014. Disponível em: https://periodicos.ufrn.br/artresearchjournal/article/ view/5275/4339. Acesso em: 10 jun. 2020. 